\title{
Pathogenesis and malignant transformation of adenomyosis (Review)
}

\author{
NATSUKI KOIKE, TAIHEI TSUNEMI, CHIHARU UEKURI, JURIA AKASAKA, \\ FUMINORI ITO, AIKO SHIGEMITSU and HIROSHI KOBAYASHI
}

\author{
Department of Obstetrics and Gynecology, Nara Medical University, Kashihara, Nara 634-8522, Japan
}

Received August 8, 2012; Accepted October 2, 2012

DOI: $10.3892 /$ or.2012.2184

\begin{abstract}
The aim of our review was to identify the current information with regard to the pathogenesis and malignant transformation of adenomyosis. The current literature was reviewed by searching MEDLINE/PubMed, using the following keywords: adenomyosis, myometrium, stromal cells, malignant transformation, pathogenesis, etiology, genome-wide and microarray. Early signs of the development of adenomyosis are considered to be the penetration of stromal cells into the inner layer of the myometrium. Adenomyosis smooth muscle cells are developed, possibly, through a remodeling pathway via reactivation of coelomic epithelial cells as a result of estrogeninduced epithelial mesenchymal transition. Smooth muscle cell hyperplasia and hypertrophy are a reflection of a reaction of the surrounding tissue. The development of adenocarcinoma arising from adenomyosis is a relatively rare occurrence. In our literature review, to date, 44 cases of malignant tumors arising from adenomyosis have been documented. Studies reporting results of genetic abnormalities, epigenetic changes, monoclonal expansion, mutational analysis and the inactivation of specific tumor suppressor genes are very few in this field. In conclusion, adenomyosis can be a precursor of some carcinomas. The exact molecular mechanisms that lead to the malignant transformation are poorly understood.
\end{abstract}

\section{Contents}

1. Introduction

2. Pathogenesis of adenomyosis

3. Histogenesis of adenomyosis

4. Malignant transformation of adenomyosis

5. Discussion

Correspondence to: Dr Hiroshi Kobayashi, Department of Obstetrics and Gynecology, Nara Medical University, 840 Shijo-cho, Kashihara, Nara 634-8522, Japan

E-mail: hirokoba@naramed-u.ac.jp

Key words: adenomyosis, malignant transformation, pathogenesis

\section{Introduction}

Adenomyosis is a common gynecological disorder; it is a myometrial lesion characterized by the presence of ectopic endometrial glands and stroma located deep within the surrounding myometrium with adjacent myometrial hyperplasia and hypertrophy (1). Symptoms are commonly reported as menorrhagia, dysmenorrhea, pelvic pain, abnormal uterine bleeding and bulk-related symptoms. Despite its common occurrence, the etiology and pathogenesis of adenomyosis remains unclear. Previous epidemiologic studies investigated risk factors for adenomyosis. Risk factors include: age between 40 and 50 years, early menarche, short menstrual cycles, a first birth at an early age, multiparity, sharp curettage during early pregnancy, obesity and tamoxifen use $(1,2)$. Adenomyosis commonly coexists with uterine leiomyomas (1).

Adenomyosis, adenomyoma and adenomyomatosis are pseudotumors of several organs, including the uterus as well as the bile ducts, gallbladder and Vater papilla $(3,4)$. Adenomyosis of the gallbladder is a benign, mostly asymptomatic condition made up of $3.3 \%$ of patients who underwent cholecystectomy (3). Histology confirmed the presence of hyperplastic change in the gallbladder wall, overgrowth of the mucosa, thickening of the muscular wall, and formation of intramural diverticula or sinus tracts, also known as the formation of Rokitansky-Aschoff sinuses $(3,5)$. Although the pathogenesis of uterine adenomyosis remains unclear, the most frequent debate is whether the pathological alteration is inflammation or adenoma (6).

\section{Pathogenesis of adenomyosis}

Myometrial dysfunction. Adenomyosis can be diagnosed using magnetic resonance imaging (MRI): irregular thickening of the junctional zone is associated with adenomyosis. Human and experimental studies suggest that adenomyosis occurs by invagination of the basal endometrium into the inner layer of the uterine myometrium known as junctional zone $(1,7)$. Abnormal thickening of the subendometrial myometrium includes basal endometrium and inner myometrium. The inner layer of the myometrium may represent a region of structural weakness and myometrial dysfunction of varying severity susceptible to an invagination of the stromal cells. The junctional zone was often found to be fissured (7). Myometrial smooth muscle dysfunction also develops as a primary or steroid hormone-induced defect 
in adenomyosis (8). Following invagination of stromal cells, invasion of glandular cells, abnormal growth and differentiation, these cells are subsequently surrounded by hypertrophic and hyperplastic myometrium $(9,10)$. These data suggest that adenomyosis might be caused by defects in the formation of the inner myometrial layer of the uterus (8).

Morphological changes are detected in the myometrial architecture of uteri having adenomyosis (11). Microscopically, spindle cell populations containing smooth muscle cells, frequent components of adenomyotic lesions, are noted in direct contact to the adenomyotic stroma (12). Expression of $\alpha$-smooth muscle actin (positive for smooth muscle cells and a contractile phenotype called myofibroblasts) and desmin, an intermediate filament (positive for skeletal, visceral and certain vascular smooth muscle cells), were consistent with myometrial hyperplasia and hypertrophy in adenomyotic myometrium (13). The vimentin expression (positive for mesenchyme origin cells) differed and was lower in adenomyosis and higher in eutopic endometrium. There was also a difference in the expression of estrogen receptor (ER) and progesterone receptor (PR) between the adenomyosis and non-adenomyosis groups such as leiomyomas (14). ER- $\beta$ expression and the lack of PR expression are related to the development of adenomyosis. Persistent estrogenic stimulation may have a functional role in the characteristic of adenomyosis due to myometrial smooth muscle cell hypertrophy and hyperplasia. It has been established, for example, that the myometrial hyperplasia during early gestation is induced by the estradiol-mediated PI3K (phosphatidylinositol-3 kinase)/mTOR (mechanistic target of rapamycin) signaling pathway (15).

Increased intrauterine pressure. Another possibility is increased intrauterine pressure (1). Increase in the growth of the uterus during pregnancy is due to smooth muscle cell hypertrophy and hyperplasia (16). Mechanical stretch is known to stimulate myometrial hyperplasia and hypertrophy through alteration of intracellular calcium signaling. Myometrial stretch and subsequent uterine contractile activity are associated with the initiation of primary dysmenorrhea. A history of severe dysmenorrhea has been associated with a subsequent diagnosis of endometriosis (17). Collectively, prolonged mechanical stretch and contraction can modulate uterine myometrial growth and subsequent hypertrophy to and hyperplasia of myometrial cells.

\section{Histogenesis of adenomyosis}

Several key steps are required to establish an adenomyosis: epithelial-mesenchymal transition (EMT), survival and growth of the ectopic tissue within the myometrium, myometrial hypertrophy and hyperplasia, and induction of an immunosuppressive microenvironment. The theory of stromal invagination into the inner layer of the myometrium with gland invasion, in conjunction with microenvironmental factors to stimulate smooth muscle cell growth, is the most widely accepted hypothesis. It is plausible that myometrial hypertrophy and hyperplasia are considered as metaplasia of stromal cells. It can also be explained by the embryonic remnants/rests theory or as response/reaction to the presence of ectopic glands. Although the exact etiology of adenomyosis is unknown, several hypotheses about its origin exist, as described below.
Metaplasia theory. Although the functional contributions of smooth muscle cells to adenomyosis development are poorly understood, Mechsner et al reported that epithelial and stromal cells in endometriosis develop from persistent coelomic epithelial cells by metaplasia (18). In pelvic endometriosis, eutopic endometrial cells arriving through retrograde transplantation at ectopic sites could induce the surrounding tissue to undergo smooth muscle metaplasia. Similar to endometriosis, adenomyosis-associated smooth muscle cells may be of metaplastic origin. In skin, fibroblast-to-myofibroblast transition is a key event during hypertrophic and keloid scar formation. Myofibroblastic metaplasia with formation of an abnormal myometrial hypertrophy may contribute to an impaired uterine function.

Immunohistochemical study in adenomyosis tissue revealed expression of specific uterine marker molecules, including the essential components characterizing uterine myometrial cells such as oxytocin receptor (OTR), vasopressin receptors (VPR), ER and PR (12). OTR, ER and PR are also expressed in peritoneal endometrial smooth muscle cells (11). The endometrial stromal cells have an elongated fibroblast-like appearance with immunopositivity for $\alpha$-smooth muscle actin, indicating a pure smooth muscle phenotype. This theory is the myofibroblastic differentiation from fibroblasts or stromal cells, suggesting smooth muscle metaplasia out of stromal cells.

Müllerian remnants theory. Another possibility is that the de novo development of adenomyosis occurs from Müllerian rests in a uterine myometrial location (1). Adenomyosis may stem from the capacity of the secondary Müllerian system to differentiate into both endometrial glands and stroma and surrounding smooth muscle cells. The deeply infiltrating retroperitoneal nodule is considered to be an adenomyosis whose pathogenesis is related to metaplasia of Müllerian remnants.

Tissue remodeling theory. On the other hand, van Kaam et al reported that the presence of adenomyotic nodules in deeply infiltrating endometriosis lesions is accounted for by a reaction of the local environment to the presence of ectopic endometrium (19). Adenomyosis is caused by trauma, known as tissue injury and repair (20). The response to any implant is wound healing comprised of inflammation and tissue remodeling. The wound healing process involves more extensive tissue remodeling through production of extracellular matrix (ECM) components, remodeling enzymes, cellular adhesion molecules, growth factors, cytokines and chemokine genes. Activated macrophages generate various cytokines including transforming growth factor (TGF)- $\beta$, which promotes tissue remodeling and subsequently causes fibroblasts to differentiate into myofibroblasts. Stromal cells were characterized as myofibroblasts due to their expression of $\alpha$-smooth muscle actin, tropomyosin, desmin and collagens (21). Myofibroblasts play an important role in the development of adenomyosis by their expression of ECM proteins. These data suggest that myometrial hypertrophy is a response/reaction of the ectopic endometrial cells to the surrounding tissue, which shares characteristics with physiological and pathological mechanisms of wound healing (tissue injury and repair) $(1,19,20)$.

The human uterine endometrium undergoes scarless repair. Chronic persistent normoperistalsis leads to the same 
extent of microtraumatization (20). This mechanism overlaps those controlling other histopathological occurrences of tissue remodeling.

Epithelial-mesenchymal transition theory. Adenomyosis is an estrogen-dependent disease. High estrogen concentrations in ectopic endometrium may be necessary for the maintenance of adenomyosis (1). The estrogen dependency is often accompanied by the appearance of EMT features, which is a crucial step for the acquisition of invasive properties of endometrial epithelial cells during adenomyosis progression (22). Estrogen enhances endometrial tissue growth, metastasis and angiogenesis in an adenomyosis model via annexin A2 (ANXA2)-induced EMT (23). These data implicate the crucial role of estrogen-induced EMT in the development of adenomyosis (22).

Multipotential perivascular theory. The phenomenon of vascular involvement in adenomyosis is relatively common. Angiogenesis is an important factor in the development of adenomyosis $(7,24)$. Vascular endothelial growth factor (VEGF), fibroblast growth factor (FGF)-1, FGF-2, thrombospondin 1 (TSP-1) and platelet-derived growth factor (PDGF) are potent angiogenic factors. The $\mathrm{FGF} 2754 \mathrm{C} / \mathrm{G}$ polymorphism is considered to be associated with a risk for developing adenomyosis in Chinese women (25). Pathophysiological vascular remodeling leads to vascular smooth muscle cell hypertrophy, proliferation, or migration (26). Angiotensin II is a well-known participant of vascular remodeling and activates a downstream target PAK1 (serine/threonine p21-activating kinase). Pak1 is a critical effector that links RhoGTPases to cytoskeleton reorganization and regulates cell motility and morphology. Expression of PAK1 is increased in adenomyosis, suggesting that PAK1 is involved in adenomyosis-associated vascular remodeling (27).

Meenakshi and McCluggage raise the possibility that mesenchymal stem-like cells reside in a perivascular niche and adenomyosis may derive from myometrial blood vessels, perhaps multipotential perivascular cells (28). Sieiński found that proliferation of the adenomyotic stroma originates from a perivascular stromal proliferation, indicating that a multipotential stem cell population within adenomyosis appears to be associated with perivascular cells surrounding the blood vessels (29). These studies suggest that the possible existence of multipotential perivascular stromal and myometrial cells is an important factor in the development of adenomyosis.

Mast cell activation theory. Mast cells are present within the endometrium and are also observed in close association with uterine smooth muscle cells (30). Activation and release of mast cell-derived mediators occur in endometriosis (31). Mast cells could contribute to the differentiation and development of the myometrium, possibly through the production of nerve growth factor (NGF), preadipocyte factor-1 (Pref-1), and insulin-like growth factor-2 $(8,32)$.

NGF plays a critical role in the production of pain and can be used as an indicator for the severity of adenomyosis. Pref-1 may have a role in maintaining cells in an undifferentiated state. These data support the hypothesis that the mast cell is an important factor in the maintenance of adenomyosis $(7,24)$.
Others. DNA microarray and proteomics analysis identified that specific genes are differentially expressed in adenomyosis and matched eutopic endometrium. Abnormalities of inflammatory response, cytokine/chemokine expression, protease activation, autophagy, immunosuppressive microenvironment and epigenetic regulation may be present in adenomyosis. Numerous genes, including CXCL10, calbindin D-28K, prostaglandinrelated factors [such as prostaglandin E receptor 3 (subtype EP3) and prostaglandin synthase], COX-2 and cancer- and cell death-related genes are differentially expressed in adenomyosis (10,33). CXCL10 modulates adhesion molecule expression through stimulation of monocytes and natural killer and T-cell migration. Patients with adenomyosis had HLA-G expression in eutopic and ectopic endometrial cells (34). This could explain the ability of cells to escape host immunosurveillance and to survive without being eliminated by the immune system. Calbindin, a cytosolic calcium binding protein, is expressed in female reproductive tissues (35). Uterine calbindin may be involved in controlling myometrial activity related with intracellular calcium level. The expression of interleukin-10 (IL-10) was elevated in the eutopic endometrium of women with adenomyosis (36). IL-10 downregulates the expression of Th1 cytokines and MHC class II antigens. The matrix metalloproteinase (MMP)-2 -1306C/T polymorphism may be associated with the risk of adenomyosis (37). COX-2 induces migration, invasion and anti-apoptotic capabilities of adenomyosis-derived mesenchymal stem cells (38). Beclin 1 has a central role in autophagy, a process of programmed cell survival, which is increased during periods of cell stress (39). Beclin 1 expression was decreased in eutopic endometria of women with adenomyosis (40). Histone deacetylases (HDACs) are involved in adenomyosis, suggesting that it may be an epigenetic disease (41). These data suggest that genetic and epigenetic abnormalities contribute to the pathogenesis of adenomyosis.

Animal experiments. The findings and theories on the pathogenesis of adenomyosis have been obtained by research using animal models. A variety of animals, including non-human primates, horses, dogs, cats, rabbits and laboratory rodents, can be used as models for developing spontaneous adenomyosis $(24,42)$. On the other hand, an animal model of endometriosis appears limited to non-human primates, since rodents do not develop spontaneous endometriosis (24). These two phenotypic variants suggest different etiology and pathophysiology of adenomyosis and endometriosis $(24,43)$. In animal models, adenomyosis was characterized by benign invasion of endometrial glands and stroma into the myometrium, growth of these cells and subsequent hypertrophy and hyperplasia of myometrial smooth muscle cells. CD-1 mice spontaneously develop uterine adenomyosis, with a disease prevalence of $\sim 80 \%$ by 12 months of age (24). Other animal experiments also showed that tamoxifen-induced disruption and disorganization of the inner myometrium play a role in the development of adenomyosis (44). Abnormal development of the inner circular muscle layer, exhibiting discontinuity in the inner myometrial layer, marked thinning, and lack of orientation and bundling of the muscle cells, may be involved in the development of premature uterine adenomyosis. Increased incidence and severity was evident in mice dosed with tamoxifen (45). Upregulated genes include nerve growth factor (NGF), cathepsin B, transforming growth 


\section{Estrogen-dependent}

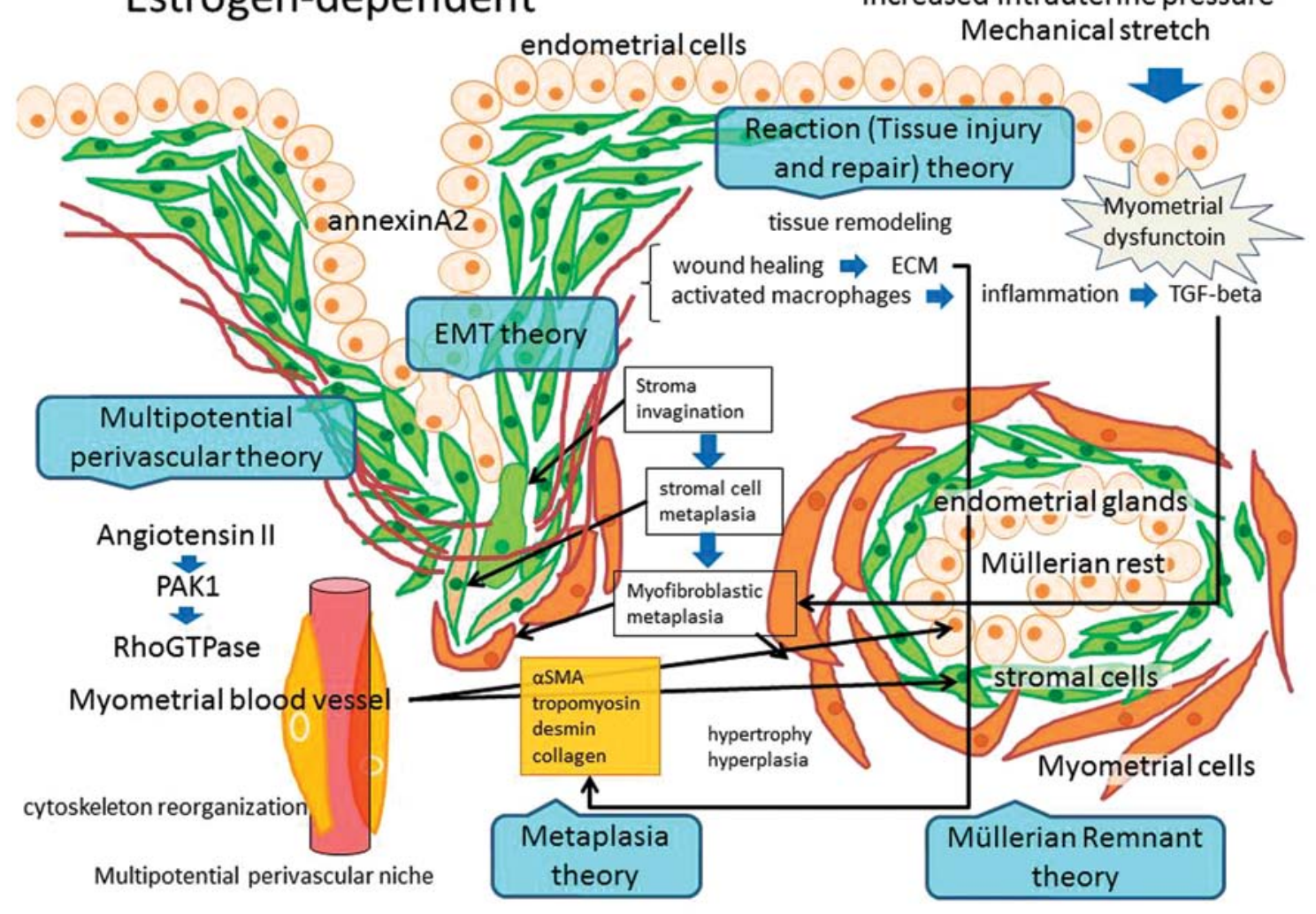

Figure 1. A proposed model of adenomyosis development. Several pathological theories of adenomyosis have been proposed: EMT, metaplasia, Müllerian rests, reaction (tissue injury and repair) and multipotential perivascular theories. Initial stromal invagination and subsequent myofibroblastic metaplasia are essential for adenomyosis development and progression.

factor- $\beta$ induced (Tqfbi) and collagens (Colla1, Colla2) (45). NGF is associated with the severity of adenomyosis and plays a critical role in producing pain, neural plasticity and release of inflammatory factors (46). In equine models, ECM proteins, including collagen IV, laminin and fibronectin deposition outside the basement membrane, might be involved in the development of endometriosis (21). These findings will be helpful to provide a molecular basis for understanding the mechanism underlying steroid hormone-induced tissue remodeling and the development of adenomyosis (45).

\section{Malignant transformation of adenomyosis}

It is believed that endometriosis can undergo malignant transformation into endometrioid and clear cell ovarian carcinoma. We reviewed whether adenomyosis serves as a precursor of neoplastic disease. Sampson's criteria were proposed for a diagnosis of malignant transformation of adenomyosis (47). Kumar and Anderson emphasized the necessity of the transitions between the benign and malignant glandular structures $(48,49)$. Colman and Rosenthal identified criteria that endometrial stromal cells supporting a diagnosis of adenomyosis must be present (50). Herein we reviewed the cases of carcinoma arising in adenomyosis.

The pathological criteria used for case identification are: i) evidence of pre-existing adenomyosis at the site of the malignant lesion; ii) presence of glandular cells and/or endometrial stromal cells supporting a diagnosis of adenomyosis; iii) evidence of transitions between the benign and malignant glandular structures; iv) carcinoma must be absent from invasion or metastasis from another source; and v) carcinoma must be absent from the eutopic endometrium.

A frequent association of adenomyosis with other hormonedependent uterine lesions, including leiomyoma, endometrial hyperplasia and endometrial carcinoma has been described in the literature $(1,51)$. Adenomyosis is commonly seen in hysterectomy specimens for endometrial adenocarcinoma $(1,51)$. Malignant changes in adenomyosis were present in 6.8\% of patients with endometrial cancer (52). A majority of cases with adenocarcinoma arising in adenomyosis were associated with the adjacent endometrial adenocarcinomas (53). Adenocarcinomas developing within adenomyosis often originate from endometrial carcinomas which arise from the eutopic endometrium, then invade into pre-existing adenomyosis (54). In this review, we selected cases whose endometrium was completely examined and tumor-free.

Although malignant transformation of adenomyosis is a rare event, there are several case reports of adenocarcinomas developing within adenomyosis. Rolly published the first report in 1897 (55). In our review, to date, 44 cases of malignant tumors arising from adenomyosis have been documented (48,51,54-70).

Most of the patients were postmenopausal. Malignant transformation of adenomyosis in premenopausal women with normal endometrium is extremely rare (54). Abnormal vaginal bleeding, vulvar itching, slight fever and weight loss were clinical presentations. These uteri showed no evidence 
of endometrial malignancy in the endometrial cavity. One patient had received tamoxifen for treatment of her breast cancer over the past five years (59). There were transitions between endometrial epithelium of adenomyosis, borderline malignancy (noninvasive), and invasive carcinoma. The histological subtypes of the tumors were endometrioid and, to a lesser degree, serous, clear cell and poorly differentiated adenocarcinoma. Serous endometrial intraepithelial carcinoma (serous EIC) arising in adenomyosis is rare $(56,59)$.

Two types of endometrial carcinoma, type I or type II, have been delineated on the basis of clinicopathological and genetic studies. In most cases with malignant transformation of adenomyosis, different stages of atypical or hyperplastic changes were simultaneously identified (52). This observation highlights a similar pathway of carcinogenesis in adenomyosis as is known in estrogen-responsive endometrial cancer type I (52). In general, malignant transformation of adenomyosis was positive for ER, PR, cyclooxygenase-2 (COX-2), CA125 and focally weak-positive for aromatase. Hormonal receptor expression is associated with low grade and early-stage tumors. Aromatase activity is upregulated by increased levels of the enzyme COX-2.

By contrast, advanced adenocarcinomas in adenomyosis were reported as negative for ER and PR (58). Ohta et al reported a case of a clear cell adenocarcinoma arising from adenomyosis, with overexpression of p53 and laminin-5 $\gamma^{2}$ chain (62). The poorly differentiated adenocarcinoma cells stained positively for p53, but did not express either ER or PR, suggesting that this adenocarcinoma was a type II carcinoma with biologically aggressive behavior (48). This has led to the proposal that some cases with malignant transformation of adenomyosis develop de novo.

\section{Discussion}

This review aimed at summarizing and emphasizing the pathogenesis of adenomyosis and its malignant transformation. Several pathological theories of adenomyosis have been proposed: i) metaplasia, ii) Müllerian rests, iii) reaction (tissue injury and repair) theory, as well as other hypotheses (Fig. 1). It is likely that intrinsic factors within the myometrium are key for the development of adenomyosis. Early signs of the development of adenomyosis might be the disruption of smooth muscle cells of the inner layer of the myometrium. Associated with these changes, stromal connective tissue penetrates into the myometrium followed by uterine gland invasion and growth. Adenomyosis-associated smooth muscle cells respond to changes in environmental factors and regulate smooth muscle function. Smooth muscle thin filaments are dynamic and remodel the actin cytoskeleton. Smooth muscle cell aggregation, hypertrophy and hyperplasia in premature uterine adenomyosis is considered as smooth muscle metaplasia with various grades of differentiation.

Recent progress in the understanding of the molecular environment surrounding adenomyosis demonstrated that growth and regression are determined by the rate of cell proliferation, differentiation, apoptosis, angiogenesis, protease production, and ECM deposition. These changes might determine the patterns of gene expression appropriate for transformation of stromal cells into functional smooth muscle cells. Ovarian steroids are key regulators of a number of these processes. Activation of several of these pathways and their downstream targeted genes are involved in regulating a wide variety of processes that regulate ovarian steroid synthesis, immune response, metabolism, matrix accumulation, angiogenesis and local inflammatory response (10). Although the full implications of the differentially expressed genes are not yet completely understood, adenomyosis samples clustered closely with endometrium samples (10). It may provide evidence for a possible metaplastic origin of endometrial stromal cells.

We reviewed cases of adenocarcinoma arising from adenomyotic foci in the uterus. Adenomyosis shares some aspects of malignancy such as increased growth, angiogenesis and invasion. The development of malignant disease is a rare occurrence. The occurrence is attributable to malignant transformation of an existing adenomyosis. Transition from endometrial epithelium of adenomyosis to the pre-malignant single-layered tumor cells, and finally to carcinoma lesions of various degrees was recognized. These processes depend on the accumulation of genetic and epigenetic alterations in a multistep process. However, the identity of molecule(s) that initiate myometrial cellular transformation and subsequently regulate their growth remains unknown. The pathological and molecular plausibility is not well substantiated.

There have been few data reporting genetic changes, mutational analysis and the inactivation of specific tumor suppressor genes in adenomyosis. Goumenou et al reported for the first time that loss of heterozygosity ( $\mathrm{LOH}$ ) occurs in adenomyosis (71). DNA mismatch repair genes (hMSH2, hMLH1), p16 ${ }^{\text {Ink4 }}$ (CDKN2A, cyclin-dependent kinase inhibitor 2A) and GALT (galactose-1-phosphate uridylyltransferase) genes were associated with adenomyosis (71). Stromal bcl-2 expression in adenomyosis remained at low levels and could have negative implications for the growth and survival of ectopic endometrial tissue (72). Although the monoclonal outgrowth of ectopic glands has been demonstrated in endometriosis, the details of the phenomenon in adenomyosis remain unknown. Adenomyosis has epigenetic aberration with respect to promoter hypermethylation of progesterone receptor (73). Epigenetic changes have to be explored in adenomyosis. However, the biological functions of several other genes in adenomyosis remain to be determined. A molecular continuum between the benign affection and the malignant entity requires stronger evidence of common mutational or methylational events.

In conclusion, adenomyosis is a common benign disease. Numerous hypotheses have been proposed to explain the presence of ectopic endometrial tissue and stroma in uterine myometrium. Perhaps the most compelling mystery surrounding adenomyosis is not why a subset of women is afflicted, but how the majority of women can prevent adenomyosis development. In the present review we also presented cases of malignant transformation, reviewing the literature for data of possible associated factors that lead to the pathogenesis of the disease. Although its course is usually benign, adenomyosis may be the precursor of malignant disease. However, to date, there has not been sufficient genetic and epigenetic evidence for malignant transformation of adenomyosis. With further research, we may come closer to identifying the pathogenesis and pathophysiology of adenomyosis and its malignant transformation. 


\section{Acknowledgements}

This study was supported by KAKENHI [Japan Society for the Promotion of Science (JSPS) Grant-in-Aid]. We thank all the study participants for their time and efforts. We thank Mikiko Kita for the editorial assistance.

\section{References}

1. Ferenczy A: Pathophysiology of adenomyosis. Hum Reprod Update 4: 312-322, 1998.

2. Templeman C, Marshall SF, Ursin G, Horn-Ross PL, Clarke CA Allen M, Deapen D, Ziogas A, Reynolds P, Cress R, AntonCulver H, West D, Ross RK and Bernstein L: Adenomyosis and endometriosis in the California Teachers Study. Fertil Steril 90: 415-424, 2008

3. Lalović N, Cvijanović R, Vladicić ND, Marić R, Jokanović D and Skipina DB: Adenomyomatosis of the gallbladder - case report. Med Pregl 64: 323-326, 2011.

4. Kayahara M, Ohta T, Kitagawa H, Miwa K, Urabe T and Murata T: Adenomyomatosis of the papilla of Vater: a case illustrating diagnostic difficulties. Dig Surg 18: 139-142, 2001.

5. Matsumoto T and Shimada K: A case of gallbladder cancer arising from the Rokitansky-Aschoff sinus. Jpn J Clin Oncol 39: 776, 2009.

6. Krutsay M: Adenomyosis of the common bile duct. Magy Onkol 54: 179-180, 2010 (In Hungarian).

7. Benagiano G, Brosens I and Carrara S: Adenomyosis: new knowledge is generating new treatment strategies. Womens Health 5: 297-311, 2009.

8. Parrott E, Butterworth M, Green A, White IN and Greaves P: Adenomyosis - a result of disordered stromal differentiation. Am J Pathol 159: 623-630, 2001.

9. Mori T, Ohta $\mathrm{Y}$ and Nagasawa H: Ultrastructural changes in uterine myometrium of mice with experimentally-induced adenomyosis Experientia 40: 1385-1387, 1984.

10. Hever A, Roth RB, Hevezi PA, Lee J, Willhite D, White EC Marin EM, Herrera R, Acosta HM, Acosta AJ and Zlotnik A Molecular characterization of human adenomyosis. Mol Hum Reprod 12: 737-748, 2006

11. Barcena de Arellano ML, Gericke J, Reichelt U, Okuducu AF, Ebert AD, Chiantera V, Schneider A and Mechsner S: Immunohistochemical characterization of endometriosis-associated smooth muscle cells in human peritoneal endometriotic lesions. Hum Reprod 26: 2721-2730, 2011.

12. Mechsner S, Grum B, Gericke C, Loddenkemper C, Dudenhausen JW and Ebert AD: Possible roles of oxytocin receptor and vasopressin-1 $\alpha$ receptor in the pathomechanism of dysperistalsis and dysmenorrhea in patients with adenomyosis uteri. Fertil Steril 94: 2541-2546, 2010.

13. Mehasseb MK, Bell SC, Brown L, Pringle JH and Habiba M: Phenotypic characterisation of the inner and outer myometrium in normal and adenomyotic uteri. Gynecol Obstet Invest 71: 217-224, 2011

14. Mehasseb MK, Panchal R, Taylor AH, Brown L, Bell SC and Habiba M: Estrogen and progesterone receptor isoform distribution through the menstrual cycle in uteri with and without adenomyosis. Fertil Steril 95: 2228-2235, 2011.

15. Jaffer S, Shynlova O and Lye S: Mammalian target of rapamycin is activated in association with myometrial proliferation during pregnancy. Endocrinology 150: 4672-4680, 2009.

16. Shynlova O, Kwong R and Lye SJ: Mechanical stretch regulates hypertrophic phenotype of the myometrium during pregnancy. Reproduction 139: 247-253, 2010.

17. Treloar SA, Bell TA, Nagle CM, Purdie DM and Green AC: Early menstrual characteristics associated with subsequent diagnosis of endometriosis. Am J Obstet Gynecol 202: 534.e1-6, 2010.

18. Mechsner S, Bartley J, Infanger M, Loddenkemper C, Herbel J and Ebert AD: Clinical management and immunohistochemical analysis of umbilical endometriosis. Arch Gynecol Obstet 280 235-242, 2009.

19. van Kaam KJ, Schouten JP, Nap AW, Dunselman G and Groothuis PG: Fibromuscular differentiation in deeply infiltrating endometriosis is a reaction of resident fibroblasts to the presence of ectopic endometrium. Hum Reprod 23: 2692-2700, 2008.

20. Leyendecker G, Wildt L and Mall G: The pathophysiology of endometriosis and adenomyosis: tissue injury and repair. Arch Gynecol Obstet 280: 529-538, 2009.
21. Walter I, Handler J, Reifinger M and Aurich C: Association of endometriosis in horses with differentiation of periglandular myofibroblasts and changes of extracellular matrix proteins. Reproduction 121: 581-586, 2001

22. Chen YJ, Li HY, Huang CH, Twu NF, Yen MS, Wang PH, Chou TY, Liu YN, Chao KC and Yang MH: Oestrogen-induced epithelial-mesenchymal transition of endometrial epithelial cells contributes to the development of adenomyosis. J Pathol 222 261-270, 2010.

23. Zhou S, Yi T, Liu R, Bian C, Qi X, He X, Wang K, Li J, Zhao X, Huang $\mathrm{C}$ and Wei Y: Proteomics identification of annexin A2 as a key mediator in the metastasis and proangiogenesis of endometrial cells in human adenomyosis. Mol Cell Proteomics 11: M112.017988, 2012.

24. Greaves P and White IN: Experimental adenomyosis. Best Pract Res Clin Obstet Gynaecol 20: 503-510, 2006.

25. Kang S, Li SZ, Wang N, Zhou RM, Wang T, Wang DJ, Li XF, Bui $\mathrm{J}$ and Li Y: Association between genetic polymorphisms in fibroblast growth factor (FGF)1 and FGF2 and risk of endometriosis and adenomyosis in Chinese women. Hum Reprod 25: 1806-1811, 2010.

26. Hinoki A, Kimura K, Higuchi S, Eguchi K, Takaguri A, Ishimaru K, Frank GD, Gerthoffer WT, Sommerville LJ, Autieri MV and Eguchi S: p21-activated kinase 1 participates in vascular remodeling in vitro and in vivo. Hypertension 55: 161-165, 2010.

27. Kim SR, Kim SH, Lee HW, Chae HD, Kim CH and Kang BM: Increased expression of p21-activated kinase in adenomyosis. Fertil Steril 94: 1125-1128, 2010.

28. Meenakshi M and McCluggage WG: Vascular involvement in adenomyosis: report of a large series of a common phenomenon with observations on the pathogenesis of adenomyosis. Int J Gynecol Pathol 29: 117-121, 2010.

29. Sieiński W: Tumor-like intravascular proliferations of the stroma in adenomyosis. Patol Pol 44: 1-4, 1993.

30. Mori A, Zhai YL, Toki T, Nikaido T and Fujii S: Distribution and heterogeneity of mast cells in the human uterus. Hum Reprod 12: 368-372, 1997.

31. Menzies FM, Shepherd MC, Nibbs RJ and Nelson SM: The role of mast cells and their mediators in reproduction, pregnancy and labour. Hum Reprod Update 17: 383-396, 2011

32. Anaf V, Chapron C, El Nakadi I, De Moor V, Simonart T and Noël JC: Pain, mast cells, and nerves in peritoneal, ovarian, and deep infiltrating endometriosis. Fertil Steril 86: 1336-1343, 2006.

33. Kusakabe KT, Abe H, Kondo T, Kato K, Okada T and Otsuki Y: DNA microarray analysis in a mouse model for endometriosis and validation of candidate factors with human adenomyosis. J Reprod Immunol 85: 149-160, 2010.

34. Wang F, Wen Z, Li H, Yang Z, Zhao X and Yao X: Human leukocyte antigen- $G$ is expressed by the eutopic and ectopic endometrium of adenomyosis. Fertil Steril 90: 1599-1604, 2008.

35. Choi KC, Leung PC and Jeung EB: Biology and physiology of Calbindin-D9k in female reproductive tissues: involvement of steroids and endocrine disruptors. Reprod Biol Endocrinol 3: 66 , 2005.

36. Wang F, Li H, Yang Z, Du X, Cui M and Wen Z: Expression of interleukin-10 in patients with adenomyosis. Fertil Steril 91: 1681-1685, 2009.

37. Kang S, Zhao X, Xing H, Wang N, Zhou R, Chen S, Li W, Zhao J, Duan Y, Sun D and Li Y: Polymorphisms in the matrix metalloproteinase-2 and tissue inhibitor of metalloproteinase-2 and the risk of human adenomyosis. Environ Mol Mutagen 49: 226-231, 2008.

38. Chen YJ, Li HY, Chang YL, Yuan CC, Tai LK, Lu KH, Chang CM and Chiou SH: Suppression of migratory/invasive ability and induction of apoptosis in adenomyosis-derived mesenchymal stem cells by cyclooxygenase-2 inhibitors. Fertil Steril 94: 1972-1979, 2010.

39. Kang R, Zeh HJ, Lotze MT and Tang D: The Beclin 1 network regulates autophagy and apoptosis. Cell Death Differ 18: 571-580, 2011.

40. Ren Y, Mu L, Ding X and Zheng W: Decreased expression of Beclin 1 in eutopic endometrium of women with adenomyosis. Arch Gynecol Obstet 282: 401-406, 2010.

41. Liu X, Nie J and Guo SW: Elevated immunoreactivity against class I histone deacetylases in adenomyosis. Gynecol Obstet Invest 74: $50-55,2012$

42. Suire RA, Goodman DG, Valerio MG, Fredrickson TN, Strandberg JD, Levitt MH, Lingeman CH, Harshbarger JC and Dawe CJ: Female reproductive system. In: Pathology of Laboratory Animals. Vol. 2. Benirschke K, Garner FM and Jones TC (eds). Springer-Verlag, New York, NY, pp1051-1262 1978. 
43. Oehler MK, Greschik H, Fischer DC, Tong X, Schuele R and Kieback DG: Functional characterization of somatic point mutations of the human estrogen receptor alpha (hERalpha) in adenomyosis uteri. Mol Hum Reprod 10: 853-860, 2004.

44. Mehasseb MK, Bell SC and Habiba MA: The effects of tamoxifen and estradiol on myometrial differentiation and organization during early uterine development in the CD1 mouse. Reproduction 138: 341-350, 2009.

45. Green AR, Styles JA, Parrott EL, Gray D, Edwards RE, Smith AG, Gant TW, Greaves P, Al-Azzawi F and White IN Neonatal tamoxifen treatment of mice leads to adenomyosis but not uterine cancer. Exp Toxicol Pathol 56: 255-263, 2005.

46. Li Y, Zhang SF, Zou SE, Xia X and Bao L: Accumulation of nerve growth factor and its receptors in the uterus and dorsal root ganglia in a mouse model of adenomyosis. Reprod Biol Endocrinol 9: 30, 2011

47. Sampson JA: Endometrial carcinoma of the ovary arising in endometrial tissue of that organ. Arch Surg 10: 1-72, 1925.

48. Motohara K, Tashiro H, Ohtake H, Saito F, Ohba T and Katabuchi H: Endometrioid adenocarcinoma arising in adenomyosis: elucidation by periodic magnetic resonance imaging evaluations. Int J Clin Oncol 13: 266-270, 2008.

49. Kumar D and Anderson W: Malignancy in endometriosis interna. J Obstet Gynaecol Br Emp 65: 435-437, 1958.

50. Colman HI and Rosenthal AH: Carcinoma developing in areas of adenomyosis. Obset Gynecol 14: 342-348, 1959.

51. Ismiil ND, Rasty G, Ghorab Z, Nofech-Mozes S, Bernardini M, Thomas G, Ackerman I, Covens A and Khalifa MA: Adenomyosis is associated with myometrial invasion by FIGO 1 endometrial adenocarcinoma. Int J Gynecol Pathol 26: 278-283, 2007.

52. Kucera E, Hejda V, Dankovcik R, Valha P, Dudas M and Feyereisl J: Malignant changes in adenomyosis in patients with endometrioid adenocarcinoma. Eur J Gynaecol Oncol 32: 182-184, 2011.

53. Hernandez E and Woodruff JD: Endometrial adenocarcinoma arising in adenomyosis. Am J Obstet Gynecol 138: 827-832, 1980.

54. Kazandi M, Zeybek B, Terek MC, Zekioglu O, Ozdemir N and Oztekin K: Grade 2 endometrioid adenocarcinoma arising from adenomyosis of the uterus: report of a case. Eur J Gynaecol Oncol 31: 719-721, 2010.

55. Rolly F: Über einen Fall von Adenomyoma Uteri, Übergang in Karzinom und Metastasenbildung. Virchows Arch 150: 555 1897 (In German).

56. Abushahin N, Zhang T, Chiang S, Zhang X, Hatch $\mathrm{K}$ and Zheng W: Serous endometrial intraepithelial carcinoma arising in adenomyosis: a report of 5 cases. Int $\mathbf{J}$ Gynecol Pathol 30: 271-281, 2011.

57. Puppa G, Shozu M,Perin T, Nomura K, Gloghini A, Campagnutta E and Canzonieri V: Small primary adenocarcinoma in adenomyosis with nodal metastasis: a case report. BMC Cancer 7 : $103,2007$.

58. Takeuchi K, Yamanaka Y, Hamana S, Ohara N and Maruo T: Invasive adenocarcinoma arising from uterine adenomyosis involving the rectosigmoid colon. Int J Gynecol Cancer 14: 1004-1006, 2004.

59. Izadi-Mood N, Samadi N, Sarmadi S and Eftekhar Z: Papillary serous carcinoma arising from adenomyosis presenting as intramural leiomyoma. Arch Iran Med 10: 2582-2560, 2007.
60. Hirabayashi K, Yasuda M, Kajiwara H, Nakamura N, Sato S, Nishijima Y, Mikami M and Osamura RY: Clear cell adenocarcinoma arising from adenomyosis. Int $\mathrm{J}$ Gynecol Pathol 28: 262-266, 2009

61. Jha P, Ansari C, Coakley FV, Wang ZJ, Yeh BM, Rabban J and Poder L: Case report: imaging of Mullerian adenosarcoma arising in adenomyosis. Clin Radiol 64: 645-648, 2009.

62. Ohta Y,Hamatani S, Suzuki T, Ikeda K, Kiyokawa K, Shiokawa A, Kushima $\mathrm{M}$ and Ota $\mathrm{H}$ : Clear cell adenocarcinoma arising from a giant cystic adenomyosis: a case report with immunohistochemical analysis of laminin-5 gamma 2 chain and p53 overexpression. Pathol Res Pract 204: 677-682, 2008.

63. Couto D, Mota F, Silva T and de Oliveira C: Adenocarcinoma arising in adenomyosis: report of an unusual case. Acta Obstet Gynecol Scand 83: 406-408, 2004.

64. Woodruff JD, Erozan YS and Genadry R: Adenocarcinoma arising in adenomyosis detected by atypical cytology. Obstet Gynecol 67: 145-148, 1986.

65. Koshiyama M, Suzuki A, Ozawa M, Fujita K, Sakakibara A, Kawamura M, Takahashi S, Fujii H, Hirano T, Okagaki A, Nagano $\mathrm{T}$ and Ban $\mathrm{C}$ : Adenocarcinomas arising from uterine adenomyosis: a report of four cases. Int J Gynecol Pathol 21: 2392-2345, 2002

66. Kuwashima Y, Uehara T, Kishi K, Tajima H, Shiromizu K, Matsuzawa $\mathrm{M}$ and Takayama S: Intramural adenocarcinoma of the uterus, arisen from adenomyosis uteri, showing unique histologic appearances. Report of two cases. Eur J Gynaecol Oncol 15: 418-423, 1994.

67. Rubod C, Narducci F, Delattre C, Decocq J, Verbert A and Delahousse G: Endometrioid adenocarcinoma arising from adenomyosis. A case report and literature review. J Gynecol Obstet Biol Reprod 33: 140-144, 2004.

68. Takai N,AkizukiS, Nasu K,Etoh Y and Miyakawa I: Endometrioid adenocarcinoma arising from adenomyosis. Gynecol Obstet Invest 48: 141-144, 1999

69. Heo SH, Lee KH, Kim JW and Jeong YY: Unusual manifestation of endometrioid adenocarcinoma arising from subserosal cystic adenomyosis of the uterus: emphasis on MRI and positron emission tomography CT findings. Br J Radiol 84: e210-212, 2011.

70. Boes AS, Tousseyn T, Vandenput I, Timmerman D, Vergote I, Moerman P and Amant F: Pitfall in the diagnosis of endometrial cancer: case report of an endometrioid adenocarcinoma arising from uterine adenomyosis. Eur J Gynaecol Oncol 32: 431-434, 2011.

71. Goumenou AG, Arvanitis DA, Matalliotakis IM,Koumantakis EE and Spandidos DA: Loss of heterozygosity in adenomyosis on hMSH2, hMLH1, p16 ${ }^{\text {Ink4 }}$ and GALT loci. Int J Mol Med 6: 667-671, 2000.

72. Jones RK, Searle RF and Bulmer JN: Apoptosis and bcl-2 expression in normal human endometrium, endometriosis and adenomyosis. Hum Reprod 13: 3496-3502, 1998.

73. Jichan Nie, Xishi Liu and Guo SW: Promoter hypermethylation of progesterone receptor isoform B (PR-B) in adenomyosis and its rectification by a histone deacetylase inhibitor and a demethylation agent. Reprod Sci 17: 995-1005, 2010. 